\title{
A review of required features for a disaster response system on top of a multi-criteria decision: a Brazilian perspective
}

\author{
Daniel Eckhardta** and Adriana Leiras ${ }^{\mathrm{a} * *}$ \\ aPontifícia Universidade Católica do Rio de Janeiro, Departamento de Engenharia Industrial, Rio de Janeiro, RJ, Brasil \\ *daneckhardt@gmail.com, **adrianaleiras@puc-rio.br
}

\begin{abstract}
Paper aims: The purpose of this paper is to analyze the current Brazilian Integrated Disaster Information System (S2iD), designed to qualify and give transparency to the disaster management in Brazil.

Originality: Providing an analysis of the system features and its prioritization, this paper can also serve as a reference for implementing software for disaster response.

Research method: To enable the S2iD evaluation, the research considers a triangulation method that includes literature review, disaster response tool assessment and a multi-criteria decision model based on interviews with specialists.

Main findings: The study could define and prioritize the most critical functionalities for a disaster response system. On top of it, four new features (Information Security, Multiuser, Donor Evaluation, History Database) not previously documented in the literature were defined as necessary to a disaster management system.
\end{abstract}

Implications for theory and practice: The detailed findings indicate ways of improvement for the S2iD.

Keywords

Humanitarian logistics. Disaster response. Software system. Multi-criteria decision-making. S2iD.

How to cite this article: Eckhardt, D., \& Leiras, A. (2018). A review of required features for a disaster response system on top of a multi-criteria decision: a Brazilian perspective. Production, 28, e20180007. https://doi.org/10.1590/01036513.20180007.

Received: Feb. 19, 2018; Accepted: May 8, 2018.

\section{Introduction}

Humanitarian Logistics (HL) comprises acquiring and delivering requested supplies and services, at the places and times they are needed, while ensuring best value for money (International Federation of Red Cross and Red Crescent Societies, 2018). The importance of this research area is related to the number of disasters reported over past few decades and its impacts. According to the latest Annual Disaster Statistical Report, published by Guha-Sapir et al. (2017), 342 natural disasters were reported in 2016 affecting 569.4 million people and generating losses of US $\$ 153.9$ billion. In Brazil, 2,072 disasters were registered in 2016 over 1,450 cities and up to U\$ 91 million was committed for actions to recover the areas affected by disasters (Brasil, 2017).

According to Van Wassenhove (2006), disasters are classified in two categories, natural or human-generated, both divided in sudden-onset disasters (e.g., tsunami, earthquakes) and slow-onset disasters (e.g., hunger, drought). The author also defines four disaster phases: (i) mitigation, includes actions to prevent or reduce the disaster impacts; (ii) preparation, considers activities to be done before the disaster strikes; (iii) response, considered the reactive phase that includes activities to save lives and preserve the human and financial resources of the affected region; and (iv) recovery, aims to recover the impacted region. Leiras et al. (2014) highlight that academic HL studies are relatively recent, but they have grown regarding quantity and relevance in recent years. Taking as basis Altay \& Green 111 (2006), Galindo \& Batta (2013) performed a literature review and showed the following 
breakdown division of papers by disaster phase: 23.9\% (mitigation), 28.4\% (preparation), 33.5\% (response), only 3.2\% (recovery) and 11\% papers related to one or more phases of the disaster.

Uncertainty is a significant issue in a disaster context. To meet the similar unknown demand disaster requirements, there are several external factors, such as security and politics, that influence and affect the response to an extreme event (Tomasini \& Van Wassenhove, 2009). Holguín-Veras et al. (2012) highlight that the problem generated by unsolicited and even unwanted gifts (e.g., drugs, foods past their expiration date) is considered the most significant obstacle to the disaster response phase, termed the "second disaster". The process of mitigating the uncertainties during the four phases (mitigation, preparation, response and recovery) of a disaster is a significant challenge in achieving a valid response, including: to prepare the environment for not known intensity of the event during the mitigation phase, the best pre-positioning of stocks during the preparation phase, the predictability of demand during the response phase and the duration of the social economic impacts during the recovery phase (Eckhardt \& Leiras, 2015).

On the other hand, a disaster brings together many different organizations with different organizational cultures (Laakso \& Palomäki, 2013). According to Fontainha et al. (2017), the stakeholders can be classified as international and local aid networks, donors, media, direct suppliers, the private sector, government, legislative and regulatory stakeholders, the military, and the beneficiary. Despite the increase in stakeholders' engagement in disaster operations, maintaining an adequate relationship among stakeholders through the different disaster stages remains a challenge due to the large number and diversity of actors with distinct organizational cultures and structures (Leiras et al., 2014). Islam \& Chik (2011) highlight that the role of electronic and communication engineering provides the most effective performance in overcoming the hazards of a disaster. For Careem et al. (2006), whereas there are various specialized components that exist, there does not exist a single cohesive system that organizations such as the United Nations Disaster Assistance and Coordination (UNDAC) can routinely deploy.

In this context, there is a need for centralized and accessible disaster response tools that, according to Eckhardt \& Leiras (2015), can be used by different organizations to avoid waste or shortage food and non-food-items, to provide a global view of the needs of multiple disasters and to enable better communication regarding the real situation of disasters through reports and performance indicators that are shared with all stakeholders, including the beneficiaries.

The purpose of this paper is to analyze the S2iD (Integrated Disaster Information System) tool according to the functionalities needed for centralized disaster response tools. Designed to integrate different areas and applications of the Brazilian Ministry of Integration, the S2iD aims to qualify and give transparency to the management of risks and disasters in Brazil. The necessary functionalities that a system must have to be more efficient during a disaster response are reviewed. By adding new HL experts to the AHP (Analytic Hierarchy Process) study presented by Eckhardt \& Leiras (2015), this paper also seeks to improve the features and functionalities prioritization findings - this hierarchy sets the operational priorities to be followed during a disaster response.

The structure of this paper is as follows: in Section 2, the research methodology is defined. In Section 3, the features and functionalities that a disaster tool should have to provide a valid disaster response are defined. In Section 4, the details concerning the interviews conducted with experts and the AHP results are presented. In Section 5, the S2iD Brazilian tool is analyzed against the study results (features and prioritization). In Section 6, the final considerations are noted.

\section{Methodology}

This paper is based on the data triangulation of the literature review, the assessment of disaster response tools and the interviews with HL experts, as also adopted by Eckhardt \& Leiras (2015).

The review and assessment of disaster response tools and features were based on the studies presented by Blecken \& Hellingrath (2008), Blecken (2010) and Eckhardt \& Leiras (2015). The research of Eckhardt \& Leiras (2015) was extended to include a deep analysis of the S2iD Brazilian disaster response tool according to the functionalities defined in this research. Additionally, the evaluation process for each selected tool was based on two work streams: (i) tools dry run (including beta versions) and (ii) available manual and/or training materials. The interviewees were chosen to have experienced experts (+10 years' experience) from private and public sectors, and at least, one representative for each type of stakeholder. To be in line with Cozzolino (2012) that define the HL stakeholders, this paper interviewed additional three experts when compared with Eckhardt $\&$ Leiras (2015), the Government, the Military and the Logistic Operator.

Based on the literature and response tools reviews, an initial list of functionalities necessary for a disaster response tool was selected and defined. In this first stage, a validation with HL specialists was conducted to complement the list of known and currently used tools during a disaster preparation and response. This mapping is intended to list each tool's features and functionalities to complement the review of the tools presented in this research. After defining the tools to be evaluated and the consolidation of their features and functionalities, a new round 
of interviews with the same specialists was conducted to identify potentially needed functionalities that were not present in the existent tools. The insertion of the new features was subsequently ratified by the experts.

The interviews followed the same process defined by Eckhardt \& Leiras (2015): (i) reviewing existing tools to be evaluated; (ii) reviewing and defining the functionalities needed for an efficient disaster response tool; and (iii) applying a multi-criteria analysis of the selected functionalities to define their hierarchy. According to Saaty (1990) the use of the hierarchical process allows the problem to divided by several steps of the target in question, which leads to better decision-making.

\section{Disaster tools feature analysis}

During a disaster response, many tools are used to serve the beneficiaries in a shortest possible time and at the same time, to provide related resources efficiently. Blecken (2010) analyzed six tools which were designed to support humanitarian supply chains: SUMA - Suministros Management System Humanitarian, LSS - Logistics Support System, Helios, Sahana, LOGISTIX, UniTrack). The author evaluated these tools according to the following functionalities: supply chain design, planning, and execution, documentation, reports, controlling, cross-linking, offline/online access, modularity/adaptability, usability, direct costs (software and hardware) and indirect costs (training, maintenance).

On top of the above functionalities, Shafiq et al. (2012) proposed the interoperability functionality, as the creation of a standard communication protocol to enable different entities to communicate during a disaster response. Eckhardt \& Leiras (2015) identified new functionalities needed in a disaster response tool: registration and management volunteers; notification management. Based on the HL interviews, four functionalities were identified: (i) security rules (for instance, to avoid hacker attacks); (ii) donor evaluation process; (iii) multi-user feature, it means, a platform with different user and roles; and (iv) historical database.

The description of the functionalities and related references selected for this study is presented in Table 1.

Table 1. Features and Functionalities of a Disaster Response Tool.

\begin{tabular}{|c|c|c|}
\hline Functionality & Reference & Description \\
\hline Supply Chain (Design) & Blecken (2010) & $\begin{array}{l}\text { Build a supply chain project targeting the strategic concept of the whole supply and demand network } \\
\text { to achieve optimal profitability. }\end{array}$ \\
\hline Supply Chain (Planning) & Blecken (2010) & Plan the supply chain tasks at strategic, tactical and operational levels to optimize the execution of processes. \\
\hline $\begin{array}{l}\text { Supply Chain } \\
\text { (Execution)) }\end{array}$ & Blecken (2010) & $\begin{array}{l}\text { Ability to manage the supply chain and the donation of funds, equipment, materials or other items } \\
\text { according to the disaster needs in the best possible way. It should have an alert management system } \\
\text { that informs users about potential bottlenecks and incidents in the overall chain. }\end{array}$ \\
\hline Documentation & Blecken (2010) & Easily accessible and friendly documentation. Documentation must be accessible online, as well as remotely. \\
\hline Reports & Blecken (2010) & Real-time reports (internal and external). \\
\hline Accessibility & Blecken (2010) & Be accessible locally and remotely. \\
\hline Controlling & Blecken (2010) & Ability to provide financial information. \\
\hline Cross-linking & Blecken (2010) & $\begin{array}{l}\text { Be intra-organizational; for instance, regional warehouses may be connected to central warehouses to } \\
\text { gain visibility into supply chain inventory. Provide cross-linking possibilities with the software used in } \\
\text { other departments of the same organization, such as human and financial resources. }\end{array}$ \\
\hline $\begin{array}{l}\text { Modularity and } \\
\text { Adaptability }\end{array}$ & Blecken (2010) & Ability to use only some modules of the proposed tool according to the disaster phase needs. \\
\hline Usability & Blecken (2010) & User-friendly interface (intuitive). \\
\hline Direct Costs & Blecken (2010) & Low costs related to software and hardware. \\
\hline Indirect Costs & Blecken (2010) & Low costs related to supporting and maintenance. \\
\hline Volunteer Registration & $\begin{array}{l}\text { Eckhardt \& } \\
\text { Leiras (2015) }\end{array}$ & Register and manage volunteers, divided among organizations and individuals. \\
\hline Notification & $\begin{array}{l}\text { Eckhardt \& } \\
\text { Leiras (2015) }\end{array}$ & Allow sending a different type of messages (text messages, email and social networks). \\
\hline Interoperability & $\begin{array}{l}\text { Shafiq et al. } \\
\text { (2012); Blecken } \\
\text { (2010) }\end{array}$ & $\begin{array}{l}\text { Ability to interact with external applications via a standardized protocol. Each entity can continue } \\
\text { working with its tool and send information into a central system. Be inter-organizational; for } \\
\text { instance, several humanitarian organizations access the same information to facilitate coordination } \\
\text { and cooperation and thus improve the operation's efficiency. }\end{array}$ \\
\hline Information Security & $\begin{array}{l}\text { Authors } \\
\text { contribution }\end{array}$ & Safety security levels according to market best practices. \\
\hline Multiuser & $\begin{array}{l}\text { Authors } \\
\text { contribution }\end{array}$ & Ability to manage multiple users at the same time, using hierarchical levels and with different user roles. \\
\hline Donor Evaluation & $\begin{array}{l}\text { Authors } \\
\text { contribution }\end{array}$ & Allow donors' evaluation of donors based on the fulfillment of agreed commitments. \\
\hline History Database & $\begin{array}{l}\text { Authors } \\
\text { contribution }\end{array}$ & Historical database for queries and comparisons between disasters for predictability studies. \\
\hline
\end{tabular}


Based on Eckhardt \& Leiras (2015), Figure 1 shows the output results of the analysis of nine tools used during a disaster response: SUMA/LSS, FEMA, Sahana, UICDSe, Donare, Helios, Google, Desiventar, and HDX. The analysis of the tools was based on two major criteria: (i) documents and sites available on the lnternet; (ii) deployment and test of the available software.

\begin{tabular}{|c|c|c|c|c|c|c|c|c|c|c|}
\hline Functionality & $\sum_{\infty}^{\infty}$ & $\sum_{i=1}^{\mathbb{I}}$ & $\frac{\sqrt{n}}{\frac{1}{4}}$ & $\begin{array}{l}\text { ڤ̆ } \\
\text { : }\end{array}$ & 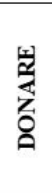 & 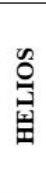 & $\begin{array}{l}\text { 됙 } \\
\text { ర్ } \\
\text { О }\end{array}$ & 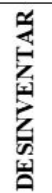 & 会 & 壳 \\
\hline Supply Chain Design & 0 & - & 0 & 0 & 0 & - & 0 & 0 & 0 & 2 \\
\hline Supply Chain Planning & 0 & - & 0 & - & 0 & - & 0 & 0 & 0 & 3 \\
\hline Supply Chain Execution & - & - & - & - & - & - & 0 & 0 & 0 & 6 \\
\hline Documentation & - & - & - & - & - & - & - & • & - & 9 \\
\hline Reports & - & - & - & - & 0 & - & 0 & - & e & 8 \\
\hline Controlling & 0 & - & 0 & 0 & 0 & $\bullet$ & 0 & 0 & 0 & 2 \\
\hline Cross-linking & 0 & - & ○ & 0 & 0 & $\bullet$ & 0 & 0 & 0 & 7 \\
\hline Offline / Online Use & 0 & - & $\bullet$ & - & 0 & - & 0 & $\bullet$ & $\bullet$ & 8 \\
\hline Modularity / A daptability & 0 & - & - & - & 0 & - & - & 0 & 0 & 7 \\
\hline Usability & 0 & - & e & 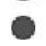 & 0 & 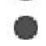 & - & - & - & 9 \\
\hline Direct Costs (Software \% Hardware) & 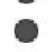 & - & 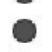 & 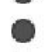 & 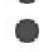 & 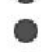 & 0 & 0 & 0 & 6 \\
\hline Indrect Costs (Training, Maintenance) & 0 & - & $\bullet$ & - & ○ & - & 0 & 0 & 0 & 6 \\
\hline Volunteer Register & 0 & 0 & $\bullet$ & 0 & O & 0 & 0 & 0 & 0 & 3 \\
\hline Notification Module (SMS, social networks ) & 0 & - & $\bullet$ & - & 0 & 0 & • & 0 & 0 & 4 \\
\hline Interoperability & 0 & 0 & $\bullet$ & 0 & 0 & 0 & 0 & 0 & 0 & 2 \\
\hline IT Security & 0 & - & $\bullet$ & O & $\bullet$ & $\bullet$ & • & 0 & 0 & 6 \\
\hline Multiuser and Hierarchical Us ers & 0 & - & 0 & e & 0 & 0 & 0 & 0 & 0 & 2 \\
\hline Donor Evaluation & 0 & 0 & 0 & 0 & 0 & 0 & 0 & 0 & 0 & 0 \\
\hline Historical Database & 9 & 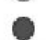 & e & 9 & 0 & e & 9 & e & 0 & 8 \\
\hline Total of Functionalities with YES & 9 & 16 & 14 & 16 & 11 & 14 & 8 & 5 & 5 & \\
\hline Total of Functionalities with $\mathrm{NO}$ & 10 & 3 & 5 & 3 & 8 & 5 & 11 & 14 & 14 & \\
\hline
\end{tabular}

Figure 1. Tools evaluation. Source: Adapted from Eckhardt \& Leiras (2015).

\section{Multi-criteria analysis}

This section presents the results obtained during interviews with experts in HL. The AHP was applied to evaluate the most critical features to be prioritized during a possible development of a disaster response tool, and, consequently, it shows what should be in focus during the operational disaster response phase.

The AHP was divided into three stages: disaster response tool as the main subject of this study; three sub-levels as Resource Management and Planning, Communication Management and Information Technology; and, below each sub-level, its corresponding functionalities. This division, as shown in Table 2, also took into consideration the critical factors to achieve the result of a disaster response proposed by Pettit $\&$ Beresford (2009).

Table 2. AHP stages.

\begin{tabular}{|c|c|c|}
\hline $\begin{array}{l}\text { Critical success factors } \\
\text { (Pettit \& Beresford, 2009) }\end{array}$ & Sub-group & Related features \\
\hline $\begin{array}{l}\text { Strategic Planning, Resource Management, } \\
\text { Transport Planning, Capacity Planning, Human } \\
\text { Resource Management, Supply Chain Strategy }\end{array}$ & Resource Management and Planning & $\begin{array}{l}\text { Supply Chain Design, Supply Chain Planning, } \\
\text { Supply Chain Execution, Controlling, Direct } \\
\text { Costs, Indirect Costs, Modularity/ Adaptability, } \\
\text { Volunteer Register }\end{array}$ \\
\hline Information management, Supplier relations & Communication Management & $\begin{array}{l}\text { Documentation, Reports, Donor Evaluation, } \\
\text { Historical Database, Notification Module, } \\
\text { Accessibility }\end{array}$ \\
\hline $\begin{array}{l}\text { Technology utilization, Continuous } \\
\text { improvement }\end{array}$ & Information Technology & $\begin{array}{l}\text { Interoperability, Cross-linking, Usability, IT } \\
\text { Security, Multiuser }\end{array}$ \\
\hline
\end{tabular}




\subsection{AHP overall results}

Table 3 shows the AHP results for Resource Management and Planning, Communication Management and Information Technology. The main focuses reported by the HL specialists are related to Communication Management and Resource Planning and Management. The maximum inconsistency logical factor value of 0.1 was considered during all interviews.

Table 3. AHP results.

\begin{tabular}{cccc}
\hline Stakeholder & $\begin{array}{c}\text { Resource Planning and } \\
\text { Management }\end{array}$ & Communication Management & Systems and Technology \\
\hline Government & 0.4740 & 0.3760 & 0.1490 \\
Aid Agencies & 0.1260 & 0.4580 & 0.4160 \\
NGO & 0.3270 & 0.4130 & 0.2600 \\
Academy & 0.1050 & 0.6370 & 0.2580 \\
Military & 0.6370 & 0.2580 & 0.1050 \\
Logistic Operators & 0.0940 & 0.6270 & 0.2800 \\
Donors & 0.4810 & 0.1140 & 0.4050 \\
\hline
\end{tabular}

In this first analysis, Communication Management stood out as the most critical aspect of a disaster response tool. In fact, Troy et al. (2008) emphasize that the ability to obtain quick and accurate information is critical to assess and respond to a crisis or disaster. Information detailing the situation of roads and highways, the number of people affected and the resource requirements (human, material, equipment, and food) is necessary to provide aid to the beneficiaries. Jahre \& Jensen (2010) reported that logistics is particularly crucial at the beginning of a crisis or disaster due to regular infrastructure disruption (for instance, seeing which roads and vehicles are still operational). Balcik et al. (2010) reported that uncertainty associated with the disaster and a lack of resources (financial, human, technological and information) creates great difficulty in coordinating humanitarian aid activities.

Table 4 shows the AHP breakdown results for the functionalities of each sub-level. The results are according to Eckhardt \& Leiras (2015) where Supply Chain Execution, Accessibility, and Usability are the basic functionalities that must be included in a Disaster Response Tool. Table 4 also shows the two most important functionalities evaluated by each stakeholder (in the grey background).

Table 4. AHP breakdown results.

\begin{tabular}{llcccccccc}
\hline \multicolumn{1}{c}{ Sub-group } & \multicolumn{1}{c}{ Functionality } & Government & $\begin{array}{c}\text { Aid } \\
\text { agencies }\end{array}$ & NGO & Academy & Military & $\begin{array}{c}\text { Logistic } \\
\text { Operator }\end{array}$ & Donor \\
& Supply Chain Design & 0.157 & 0.233 & 0.112 & 0.040 & 0.211 & 0.108 & 0.114 \\
Resource & Management & Supply Chain Planning & 0.132 & 0.143 & 0.077 & 0.137 & 0.211 & 0.095 & 0.114 \\
and Planning & Supply Chain Execution & 0.252 & 0.098 & 0.338 & 0.137 & 0.211 & 0.101 & 0.265 \\
& Controlling & 0.078 & 0.076 & 0.263 & 0.128 & 0.105 & 0.123 & 0.202 \\
& Direct Costs & 0.114 & 0.061 & 0.073 & 0.080 & 0.045 & 0.201 & 0.043 \\
& Indirect Costs & 0.114 & 0.041 & 0.061 & 0.068 & 0.045 & 0.129 & 0.023 \\
& Modularity / Adaptability & 0.113 & 0.329 & 0.032 & 0.387 & 0.049 & 0.122 & 0.065 \\
& Volunteer Register & 0.039 & 0.019 & 0.044 & 0.022 & 0.123 & 0.122 & 0.174 \\
Communication & Documentation & 0.178 & 0.036 & 0.323 & 0.072 & 0.301 & 0.062 & 0.025 \\
Management & Reports & 0.125 & 0.105 & 0.130 & 0.184 & 0.120 & 0.212 & 0.135 \\
& Donor Evaluation & 0.085 & 0.071 & 0.095 & 0.030 & 0.046 & 0.147 & 0.130 \\
& Historical Database & 0.117 & 0.302 & 0.060 & 0.184 & 0.086 & 0.087 & 0.250 \\
& Notification Module & 0.117 & 0.257 & 0.041 & 0.050 & 0.233 & 0.222 & 0.038 \\
& Accessibility & 0.378 & 0.230 & 0.351 & 0.480 & 0.215 & 0.270 & 0.422 \\
\hline Information & Interoperability & 0.141 & 0.062 & 0.533 & 0.220 & 0.139 & 0.141 & 0.071 \\
\hline Technology & Cross-linking & 0.136 & 0.070 & 0.058 & 0.124 & 0.056 & 0.131 & 0.197 \\
& Usability & 0.300 & 0.384 & 0.184 & 0.561 & 0.226 & 0.096 & 0.042 \\
& IT Security & 0.300 & 0.140 & 0.073 & 0.061 & 0.507 & 0.396 & 0.580 \\
\hline & Multiuser & 0.123 & 0.344 & 0.152 & 0.035 & 0.072 & 0.236 & 0.111 \\
\hline
\end{tabular}


The Supply Chain (Execution) primarily consists of operational level decisions. For Balcik et al. (2008), the primary needs at this level are supply allocation, scheduling delivery of vehicles and delivery routing. The same authors also state that the effective allocation of supplies in demand regions is vital during emergency situations due to the risks associated with not meeting the demand. For Blecken \& Hellingrath (2008), some features developed in the Supply Chain (Planning) could be used to improve the supply chain (Execution) - for instance, the implementation of automatic generation of purchase orders when the stock level of a specific item is reached, or the scheduled delivery is considering different routes (and their associated costs).

The Accessibility functionality is essential for a disaster response tool, as post-disaster conditions often do not provide Internet connectivity-thus, the tool must be capable of operating in two modes: remotely (via an Internet connection) and locally (no Internet connection). This concept is ratified by Blecken \& Hellingrath (2008), who notes that in a crisis, Internet connections are not always available, so it is essential for any disaster response tool to offer a way to perform even under conditions of delayed synchronization (i.e., data can be collected locally now and synchronized later when an Internet connection is available).

For Blecken \& Hellingrath (2008), the feature Usability is especially vital in the HL chain, as logistics operators typically do not have appropriate training. The tool needs to be intuitive and possess a user-friendly graphical interface. Usability also provides for a reduction in training efforts and results in a reduction in the overall costs of providing aid to those affected by a disaster.

The highlighted secondary features observed are Supply Chain (design), Documentation, Notifications, Historical Database and Information Security. The last two have a strong dependency on the technology to be used and are innovative, according to their characteristics identified during the interviews with HL experts.

The Historical Database will enable predictability studies because it contains information from various disasters in a centralized way, avoiding a lack or excess of resources, as it will facilitate information sharing. During the Katrina disaster, which occurred in the United States in 2005, Troy et al. (2008) proposed the use of a local information system drawing on a shared, centralized database; as a result, the staff and volunteers were able to successfully manage and monitor the available resources and use them in a more efficient manner when compared with previously used systems.

The Information Security feature is intended to prevent significant disasters-preventing, for instance, hacker attacks into the disaster response system. Careem et al. (2006) cite that a typical requirement of information security is the protection of pages that contain sensitive data from anonymous or unauthorized users. The general concept discussed by HL specialists is to establish security mechanisms according to market best practices and in keeping with technology evolution.

To summarize and illustrate the results of the AHP, Figure 2 shows, in ascending order (zero means low importance, five means very important), the most important features per the interviews. It is noted that Volunteer Registration and Donor Evaluation are very important for a disaster response system.

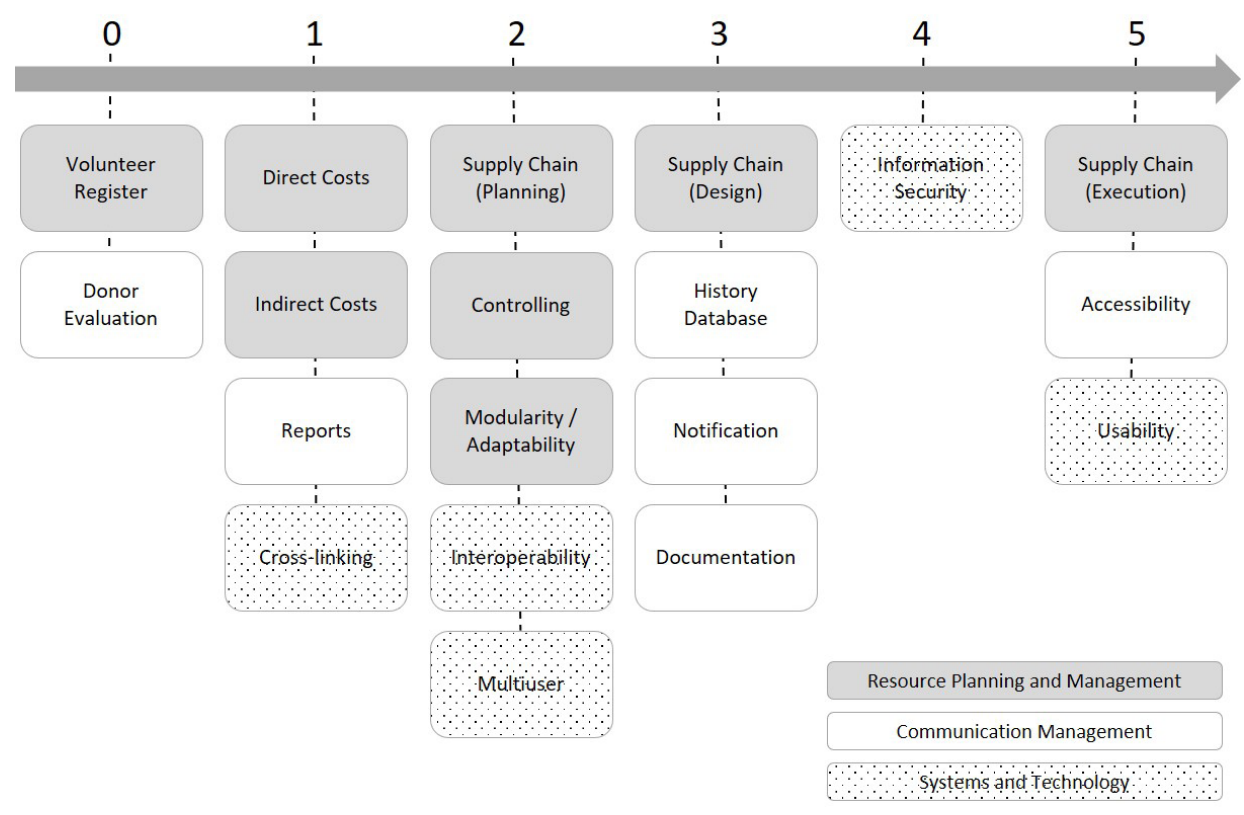

Figure 2. Priority features summary. 


\subsection{Brazilian perspective}

This section describes a Brazilian perspective through the analysis of the S2iD (Integrated Disaster Information System) tool used by the Ministry of Integration (MI) to attend municipalities in case of disasters. The Brazilian federal government officially recognized that natural disasters caused 183 deaths and affected up to 18 million people in 2013 (Brasil, 2014). According to Brasil (2017), the S2iD tool aims to integrate several systems and products targeting to offer a disaster management support tool and consequently, in the long term, create a historical disaster database that can be used for future predictability and risk management studies. Since 2014 the Ml set a KPI (Key-Performance-Indicator) to measure the access of the municipalities to the S2iD platform, the latest index, from 2016, showed that 64.93\% from 5,570 Brazilian municipalities have access to the system (Brasil, 2017), which represent a very low level of accession if we compare with 2014 index (56.91\%).

S2iD data source is based on national census information and documents generated by each county/state in case of emergency state or public calamity decrees - FIDE (Disaster Information Form), DMATE (Municipal Declaration of Emergency Action) and DEATE (State Declaration of Emergency Action) - which contain quantitative information of damages and losses.

The S2iD has a public URL (https://s2id.mi.gov.br/) where any user can see, through a high definition map, all active (registered) disasters in Brazil, including the following information on disaster type, location, and date of the disaster. Users can also navigate through reports, historical series (since 2013, when S2iD was created) and have access to official FIDE documents. There are a login and password for restrict access with different user profiles for those responsible for registering and managing the disasters. S2iD is designed to work in online mode so, each city affected by a disaster is able to enter initial information about the disaster if an Internet connection is available.

The system does not calculate the disaster needs, the municipalities are responsible for doing it through FIDE, DMATE and DEATE documents - it means that S2iD register the disaster needs and a technical responsible will manually, based on internal processes, verify if the municipality request is consistent.

To attend the municipality needs, two types of disaster support are managed inside S2iD: humanitarian emergency kits and financial resources. The decision to send financial or material resources in a disaster response does not have a standardized structure in normative instruction. Despite this, it is observed consistency of the criteria considered in this decision, for instance: local administrative capacity, local supply capacity, response time, cost and suitability of the kit. In case of sending material resources, the Ml has in place contracts with external entities that will be responsible for delivering the resources to the beneficiaries (per a pre-defined SLA - Service Level Agreement). In this case, the supply chain management can be considered outsourced, the contracted entities are responsible for performing the best logistics transportation plan according to the available modals (helicopters, trucks, cars, and ships) - this approach can be risky in case the outsourced company, for instance, fails to deliver the material resources (time, quantity, etc.). In this case, the company will be included in a government black list, and the contract is terminated.

The high-level workflow inside the S2iD tool is described herein. The end user (for instance, a member of municipal Civil Defense) should login into the system and, based on the login, some automatic information will be populated into the FIDE (city location, population, financial reports). The disaster information should be filled, - disaster type (flood, landslide, dry), duration, date and time. The next step is to enter the damage and loss information related to the affected area. Through a dynamic map, the user can define the affected region, also informing if it is a rural or urban area. The system foresees several fields to be filled regarding damages, divided into (i) human damages - number of dead, sick, affected, injured, homeless, disappeared and displaced people; (ii) material damage - number of destroyed and damaged houses/builds, public building (schools, hospitals etc.) and public infrastructure (such bridges, roads etc.). End user can also enter information on private and public losses into the system (for instance, agriculture, livestock, industry economic impacts). Based on the available information, technical analysis will be done to validate if the municipality can manage the disaster or a Federal aid is needed. If Federal aid is approved, the municipality will receive the related support respecting the current legislation and the internal Brazilian government workflow bureaucracy.

The following features are out of scope of S2iD: voluntary registration and interoperability (ability to communicate with different aid entities/organization outside public/government network). These two features could mitigate lack/excess of humanitarian needs and resources, equipment, and materials - in the first moment after a disaster, driven by media, there is a national uproar, where different stakeholders are mobilized to provide relief and assistance to those affected by sending various aid items (water, food, clothing, etc.) and, if this process is not coordinated, a second disaster may happen (as described by Holguín-Veras et al., 2012). 
Finally, S2iD still needs to improve to meet the general goals of a disaster response system. Some improvements were implemented, such as the digitization of Disaster Reports, Regional Contingency Plans module and the web base interface to register new disasters. According to Eckhardt \& Leiras (2015), the system fails in two critical functionalities as per AHP process prioritization, it is not designed to be a supply chain management, which is a must to attend the disaster beneficiaries and it does not have an off-line feature. The system is also not designed to permit population access to disaster reports (needed donations, statistics, etc.) - which would be an important feature for transparency. The Table 5 summaries the S2iD features - the Direct and Indirect Costs were not evaluated due high complexity, for instance, Brasil (2017) reports a total investment of \$200.000 in the S2iD, but it does not detail the cost type.

Table 5. S2iD features.

\begin{tabular}{|c|c|c|}
\hline Functionality & S2iD & Description \\
\hline Supply Chain (Design) & Not Compliant & - \\
\hline Supply Chain (Planning) & Not Compliant & - \\
\hline Supply Chain (Execution)) & Not Compliant & - \\
\hline Documentation & Compliant & $\begin{array}{l}\text { There are several manuals and training material available in the lnternet (http://www. } \\
\text { integracao.gov.br). }\end{array}$ \\
\hline Reports & Partially Compliant & $\begin{array}{l}\text { There are several reports available into the system, including total disasters per region, } \\
\text { damage and loss per region, summary reports, etc. Online reports related to the disaster } \\
\text { response or/and recovery are still not available, compromising transparency of the tool. }\end{array}$ \\
\hline Accessibility & Partially Compliant & The system does not work in off line mode \\
\hline Controlling & Compliant & The system foresees a financial controlling module with restrict access. \\
\hline Cross-linking & Partially Compliant & $\begin{array}{l}\text { The system only connects with IBGE (Brazilian Institute of Geography and Statistics). } \\
\text { lt would be necessary to expand this network including other stakeholders. }\end{array}$ \\
\hline Modularity and Adaptability & Compliant & $\begin{array}{l}\text { The system contains different modules such Reports, Disaster Registration, Training } \\
\text { Documents, Legislation, Geospatial Analysis, Contingency Plan, Resourcing. }\end{array}$ \\
\hline Usability & Compliant & $\begin{array}{l}\text { The system has a friendly User Interface. A responsive development method could be } \\
\text { applied to allow different devices access (for instance, via mobile). }\end{array}$ \\
\hline Direct Costs & Not Evaluated & - \\
\hline Indirect Costs & Not Evaluated & - \\
\hline Volunteer Registration & Not Compliant & - \\
\hline Notification & Not Compliant & $\begin{array}{l}\text { There is an ongoing national project that will provide SMS message alerts to mobile } \\
\text { phones of the population to the population in risk areas. It would be essential to } \\
\text { enhance the notification methods to include other Social Media. }\end{array}$ \\
\hline Interoperability & Not Compliant & - \\
\hline Information Security & Compliant & $\begin{array}{l}\text { Based on login and password, S2iD covers the minimum-security rules scenario. } \\
\text { lt would be important to have an external evaluation, for instance, penetration tests } \\
\text { that simulates an attack on the application to determine the effectiveness of its security } \\
\text { controls. }\end{array}$ \\
\hline Multiuser & Compliant & $\begin{array}{l}\text { The system is designed to have different profiles with different roles and actions. } \\
\text { For instance, a certain user just has read privileges or can access the report module. }\end{array}$ \\
\hline Donor Evaluation & Not Compliant & - \\
\hline History Database & Compliant & Since 2013 the data is being populated into the system with same standards \\
\hline
\end{tabular}

\section{Conclusions}

This study aimed to evaluate the S2iD platform, used by the Brazilian Ministry of Integration to register and attend disaster needs. A useful tool is indispensable for the quick and efficient support of the victims of disaster situations and allows to meet necessary requirements related to access, robustness, persistence, high availability, reliability and performance to meet the needs of one or more disasters.

This paper has fulfilled its primary objective by proposing the needed features and its prioritization for a disaster response tool based on three types of evidence (literature review, review of existing tools and interviews with experts) to make the study consistent.

Based on the AHP application with experts, the three main features of a disaster response software were Supply Chain (Execution), Usability, and Accessibility. Additionally, this study contributes to defining four new features required for a disaster response framework: multi-user, information security, historical database and donor evaluation. The study also showed a lack of communication between humanitarian logistics stakeholders, as various tools have been created independently and according to the needs of each entity - even including the same features developed in different tools. 
It was concluded that the S2iD still needs improvements (for instance, supply chain management feature) to be a centralized disaster management tool. It is also highlighted the need to integrate the S2iD with different stakeholders to better attend the beneficiaries.

Because technology is continually evolving, we recommend frequent evaluations of the presented tools and possible new systems or new concepts, such as the Internet of Things (loT), Big Data (Akter \& Wamba, 2017), crowdsourcing (Deng et al., 2016) that for sure will positively impact the disaster response. Some limitations of the study are highlighted: application of AHP to more stakeholders and the economic feasibility of a possible solution (software development, licenses, necessary hardware and maintenance costs) based on the features showed herein. As a complementary work, the creation of a detailed requirements catalog with the system's technical specifications (programming language, graphical interface requirements, security policy, relationship and dictionary database) is suggested.

\section{References}

Akter, S., \& Wamba, S. F. (2017). Big data and disaster management: a systematic review and agenda for future research. Annals of Operations Research. In press. http://dx.doi.org/10.1007/s10479-017-2584-2.

Altay, N., \& Green III, W. (2006). OR/MS research in disaster operations management. European Journal of Operational Research, 175(1), 475-493. http://dx.doi.org/10.1016/j.ejor.2005.05.016.

Balcik, B., Beamon, B. M., \& Smilowitz, K. (2008). Last Mile distribution in humanitarian relief. Journal of Intelligent Transport Systems, 12(2), 51-63. http://dx.doi.org/10.1080/15472450802023329.

Balcik, B., Beamon, B. M., Krejci, C. C., Muramatsu, K. M., \& Ramirez, M. (2010). Coordination in humanitarian relief chains: practices, challenges, and opportunities. International Journal of Production Economics, 126(1), 22-34. http://dx.doi.org/10.1016/j.jpe.2009.09.008.

Blecken, A. (2010). Humanitarian logistics: modeling supply chain processes of humanitarian organizations (Kuehne Foundation Book Series on Logistics, Vol. 18). Berne: Haupt-Verlag.

Blecken, A., \& Hellingrath, B. (2008). Supply chain management software for humanitarian operations: review and assessment of current tools. In Proceedings of the 5th International ISCRAM Conference. Washington: ISCRAM. Retrieved in 2017, August 21, from http:// www.iscram.org/legacy/dmdocuments/ISCRAM2008/papers/ISCRAM2008_Blecken_etal.pdf

Brasil, Ministério da Integração Nacional, Secretaria Nacional de Defesa Civil, Centro Nacional de Gerenciamento de Riscos e Desastres. (2014). Anuário Brasileiro de Desastres Naturais 2013. Brasília: CENAD.

Brasil, Ministério da Integração Nacional. (2017). Sistema Integrado de Informações sobre Desastres - S2ID. Brasília. Retrieved in 2017, August 21, from http://www.mi.gov.br/defesa-civil/s2id

Careem, M., Silva, C., Silva, R., Raschid, L., \& Weerawarana, S. (2006). Sahana: overview of a disaster management system. In Proceedings of the International Conference on Information and Automation. Colombo: ICINFA. http://dx.doi.org/10.1109/ICINFA.2006.374152

Cozzolino, A. (2012). Humanitarian logistics: cross-sector cooperation in disaster relief management. Berlin: Springer-Verlag. http:// dx.doi.org/10.1007/978-3-642-30186-5

Deng, Q., Liu, Y., Zhang, H., Deng, S., \& Ma, Y. (2016). A new crowdsourcing model to assess disaster using microblog data in typhoon Haiyan. Natural Hazards, 84(2), 1241-1256. http://dx.doi.org/10.1007/s11069-016-2484-9.

Eckhardt, D., \& Leiras, A. (2015). A disaster management framework based on the overview of the existent tools on top of a multi-criteria decision. In Proceedings of the 26th Annual POMS Conference. Washington: Production and Operations Management Society.

Fontainha, T. C., Leiras, A., Bandeira, R. A. M., \& Scavarda, L. F. R. R. (2017). Public-private-people relationship stakeholder model for disaster and humanitarian operations. International Journal of Disaster Risk Reduction, 22, 371-386. http://dx.doi.org/10.1016/j. ijdrr.2017.02.004.

Galindo, G., \& Batta, R. (2013). Review of recent developments in OR/MS research in disaster operations management. European Journal of Operational Research, 230(2), 201-211. http://dx.doi.org/10.1016/j.ejor.2013.01.039.

Guha-Sapir, D., Hoyois, P. H., \& Below, R. (2017). Annual disaster statistical review 2016: the numbers and trends. Brussels: Centre for Research on Epidemiology of Disasters.

Holguín-Veras, J., Jaller, B., Van Wassenhove, L. N., Perez, N., \& Wachtendorf, T. (2012). On the unique features of post-disaster humanitarian logistics. Journal of Operations Management, 30(7-8), 494-506. http://dx.doi.org/10.1016/j.jom.2012.08.003.

International Federation of Red Cross and Red Crescent Societies. (2018). Humanitarian logistics. Geneva: IFRC. Retrieved in 2018 , March 1, from http://www.ifrc.org/en/what-we-do/logistics/

Islam, S. M. T., \& Chik, Z. (2011). Disaster in Bangladesh and management with advanced information system. Disaster Prevention and Management: An International Journal, 20(5), 521-530. http://dx.doi.org/10.1108/09653561111178952.

Jahre, M., \& Jensen, L. M. (2010). Coordination in humanitarian logistics through clusters. International Journal of Physical Distribution \& Logistics Management, 40(8/9), 657-674. http://dx.doi.org/10.1108/09600031011079319.

Laakso, K., \& Palomäki, J. (2013). The importance of a common understanding in emergency management. Technological Forecasting \& Social Change Journal, 80(9), 1703-1713. http://dx.doi.org/10.1016/j.techfore.2012.12.012.

Leiras, A., Brito Junior, 1., Queiroz Peres, E., Rejane Bertazzo, T., \& Tsugunobu Yoshida Yoshizaki, H. (2014). Literature review of humanitarian logistics research: trends and challenges. Journal of Humanitarian Logistics and Supply Chain Management, 4(1), 95-130. http://dx.doi.org/10.1108/JHLSCM-04-2012-0008.

Pettit, S. J., \& Beresford, A. (2009). Critical success factors in the context of humanitarian aid supply chains. International Journal of Physical Distribution \& Logistics Management, 39(6), 450-468. http://dx.doi.org/10.1108/09600030910985811. 
Saaty, T. L. (1990). How to make a decision: the analytic hierarchy process. European Journal of Operational Research, 48(1), 9-26. http://dx.doi.org/10.1016/0377-2217(90)90057-l.

Shafiq, B., Ae Chun, S., Atluri, V., Vaidya, J., \& Nabi, G. (2012). Resource sharing using UICDSTM framework for incident management. Transforming Government: People, Process and Policy, 6(1), 41-61. http://dx.doi.org/10.1108/17506161211214813.

Tomasini, R. M., \& Van Wassenhove, L. N. (2009). From preparedness to partnerships: case study research on humanitarian logistics. International Transactions in Operational Research, 16(5), 549-559. http://dx.doi.org/10.1111/j.1475-3995.2009.00697.x.

Troy, D. A., Carson, A., Vanderbeek, J., \& Hutton, A. (2008). Enhancing community-based disaster preparedness with information technology. Disasters, 32(1), 149-165. http://dx.doi.org/10.1111/j.1467-7717.2007.01032.x. PMid:18217923.

Van Wassenhove, L. N. (2006). Blackett Memorial Lecture, humanitarian aid logistics: supply chain management in high gear. The Journal of the Operational Research Society, 57(5), 475-489. http://dx.doi.org/10.1057/palgrave.jors.2602125. 